\title{
Designing \& implementing role play as a method of teaching biochemistry for first MBBS students
}

\author{
Smita G Narad ${ }^{1, *}$, Suresh Chari ${ }^{2}$, Madhur Gupta ${ }^{3}$ \\ ${ }^{\mathbf{1}}$ Associater Professor, ${ }^{2}$ Director Medical Education Unit \& Research, ${ }^{\mathbf{3}}$ Professor and Head, N K P Salve Institute of Medical Sciences, \\ Nagpur, Maharashtra, India
}

* Corresponding Author: Smita G Narad

Email: smita_pakhmode@yahoo.com

\begin{abstract}
Introduction: DE novo synthesis of fatty acid is one of the complex metabolic pathway amongst the Biochemistry curriculum for first MBBS students. Fatty acid synthase multi enzyme complex (FAS-MEC) is key enzyme and teaching its three-dimensional structure, its loading with substrate and reactions of this pathway has been a challenge for teachers.

Objectives: Our study aims at designing role play as a teaching learning method to illustrate and simplify De novo synthesis of fatty acid. The objectives were to analyze the perception of first M.B.B.S. students and teachers about role play as a method of teaching.

Materials and Methods: Role play was designed to illustrate structure and function of FAS-MEC. 12 students from first MBBS enacted the role of various enzymes of FAS-MEC and the metabolites of the pathway. Biochemical reactions were demonstrated with help of the placards. Views of 150 Students and 10 teachers were analyzed with help of Likert's score based pre-validated questionnaire.

Results and Discussion: Teaching by role play was highly appreciated by the students \& teachers as it helped them to understand mechanism of FAS -MEC \& structure. They felt that it may improve their retention of knowledge and enhance reproducibility with effective teacher student communication. In accordance with the past studies, both group felt that role play is an effective teaching learning tool and power point presentations can be used to reinforce the topic.

Conclusion: Despite growing digitalization constitutional methods of teaching like role play is appreciated by students and teachers as a useful and effective teaching learning tool.
\end{abstract}

Keywords: Biochemistry, Fatty acid synthase multi enzyme complex, Role play, Teaching learning tool.

\section{Introduction}

Biochemistry is a fundamental basic science subject taught to first MBBS students along with Anatomy \& Physiology. Biochemistry is a volatile subject as it includes various complex metabolic pathways with numerous substrates, products, regulatory enzyme \& coenzyme. Moreover, intricate relationships of pathways, their integrations \& regulations add up to the confusion to the students. Though lecture is the most popular method of large group teaching, most of the times it becomes a passive form of learning. Hence innovations in teaching learning methods are required to make lectures interactive. ${ }^{1}$

Various methods of active teaching learning tools have been tried in the subject to make subject illustrative and simple like Problem based learning, Case Based Learning, Students seminar, Integrated teaching. ${ }^{2}$

Role play is one of the traditional teaching learning tool usually used to enhance communication skills in the medical students. ${ }^{3-5}$ Metaphorical role play is the type where students portray specific parts of a process and interact with each other to demonstrate the processes or pathways which can be used to visualize the concepts. ${ }^{5}$ Role-play, can be either inter- active whereby participants act out the role of a character in a situation following a set of rules, or noninteractive whereby a presentation is made by a participant who has adopted a character. ${ }^{6}$

Role-play is used as a training method to acquire knowledge, attitudes and skills in a range of disciplines and with learners of different ages. ${ }^{7}$ It can be used as an extremely effective tool for teaching of clinical medicine as it causes significant improvements in cognitive, psychomotor \& affective domain. ${ }^{5,8}$ Moreover, role play involves students with their active participation leading to improved teacher student communication. ${ }^{9}$ Role play has been tried as teaching learning tool in few subjects for medical students including Biochemistry. ${ }^{10-12}$ However, teaching full metabolic pathway by the role play is not yet documented in the biochemistry.

DE novo synthesis of fatty acid is one of the complex metabolic pathway involving Fatty Acid synthase multi enzyme complex (FAS MEC). The concept of multi enzyme complex and its working was difficult to elaborate. Explaining three-dimensional structure of FAS-MEC, difference in anatomical and functional components of FAS is tedious task to illustrate on blackboard and LCD. Loading of FAS complex with different metabolite and their biochemical reactions using different parts of FAS needs an extra efforts and reemphasis. ${ }^{13,14}$ Proper understanding of the pathway forms the basic site for the action of frequently prescribed hypolipidemic drugs \& their regulations. Moreover, academic weightage of the topic can be judged by frequently asked question in theory examination in all forms.

Teaching DE novo synthesis of fatty acid used to be challenging task while teaching lipid metabolism. As an attempt to help students to visualize the structure of FASMEC and its working, spontaneous role play with five students explaining loading of fatty acid synthase complex was tried. Though it was designed on spot, the rounds of applause by the students inspired and triggered us to develop a full pathway using role play for the next year batch of students. 


\section{Aims and Objectives}

Aim

The aim of present study was to design role play to teach the concept of multi enzyme complex along with its components and illustrate reactions on FAS MEC complex for the DE novo synthesis of Fatty acids.

The associated objectives of present study were:

1. To know the perception of students and teachers about use of role play as teaching learning tool.

2. To assess the perception of students and teachers use of power point presentation for concept reinforcement.

\section{Methods}

After the approval from institutional ethical committee, the present study was conducted amongst first MBBS students of 2015- 16 batch in NKP SIMS \& RC, Nagpur. 12 students volunteered and participated in the study. Students were briefed about the project and its design. After brainstorming sessions about designing of the role play, roles were allotted to the students. Placards of all enzyme of multi enzyme complex, substrate, products and coenzyme were prepared. Students not only participated but contributed in designing of the pathway by role play. Three practice sessions were held. After brief introduction regarding topic, its significance, students presented role play in the class room in front of 140 students. Ten teachers from other preclinical departments were invited and their perception was assessed.

\section{Step 1 Demonstration of Enzymes of FAS-MEC}

DE novo synthesis of fatty acid is characterized by its key enzyme that is Fatty acid synthase multi enzyme complex. FAS MEC is a dimer each having 7 enzymes with one Acyl carrier protein. A functional unit and its enzyme was demonstrated by students holding placards. (Fig. 1A \& 1B)

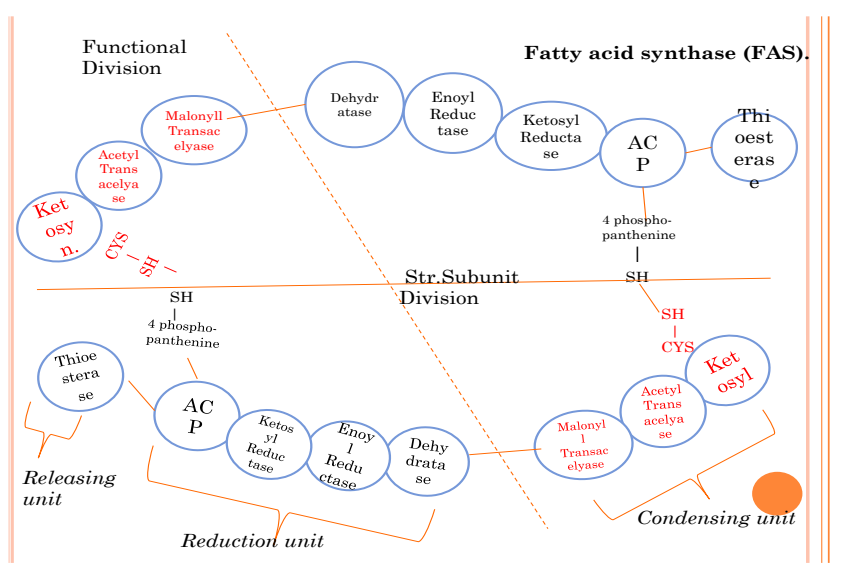

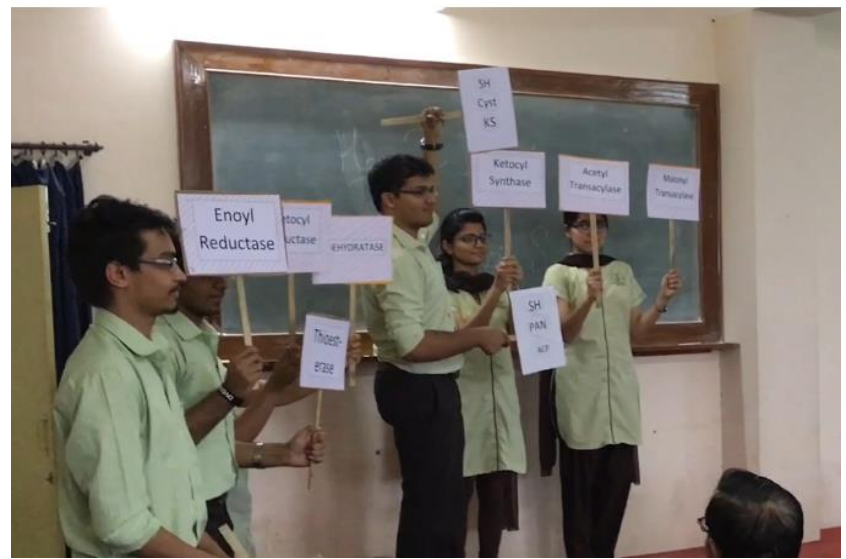

Fig. 1B

\section{Step2: Describing three-dimensional structure of FAS- MES}

Demonstration of three-dimensional structure was necessary to be imprinted on the student's mind to understand the concept of working of FAS-MEC. (How 2 moles of palmitic acid are synthesized at once). Two students enacted as short hand model of FAS-MEC to show the alignment of dimer and how it acts as anchor to hold metabolites of the pathway. (Fig. 2A \& 2B)

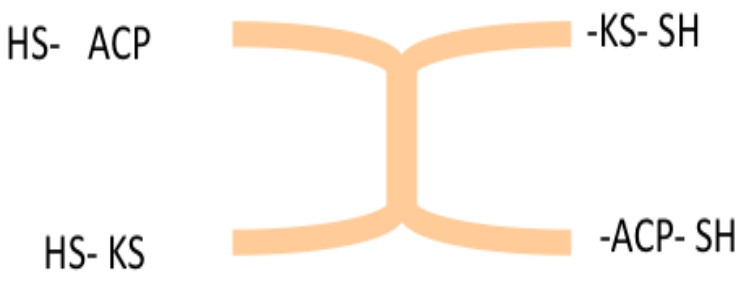

\section{Short hand model of MEC- FAS}

Fig. 2A

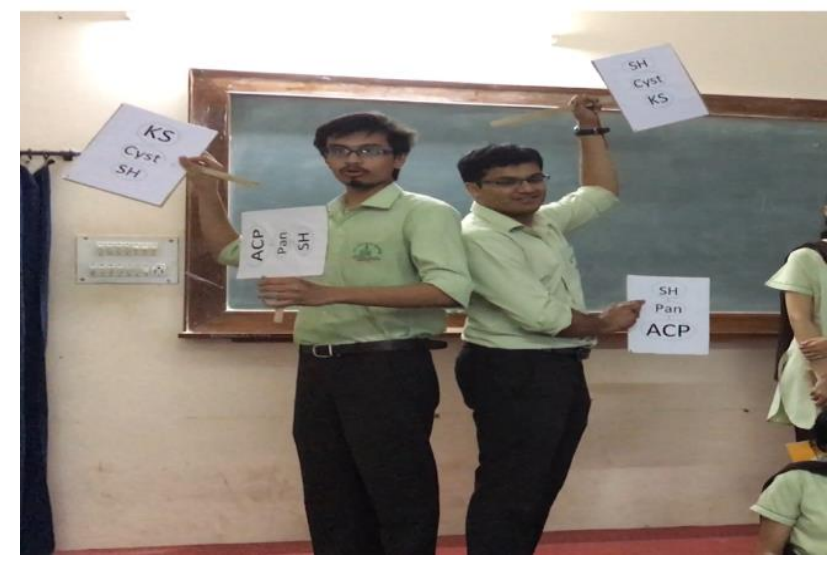

Fig. 2B 


\section{Step 3: Enacting the Metabolic Pathway}

Four students holding placards of names of the seven enzymes sat on the dais representing enzymes of FASMEC. Other 4 students standing on a dais enacted as intermediate products formed, one more students helped in removal $\&$ addition of water molecule as well as reducing equivalents involved during the pathway. Whole pathway was gradually portrayed with individual student's narrations and use of placards interchanging position of metabolic intermediate, repetition of cycles up till the synthesis 16 carbon palmitic acid \& its release from FAS MEC were shown by students. (Fig. 3A \& 3B)

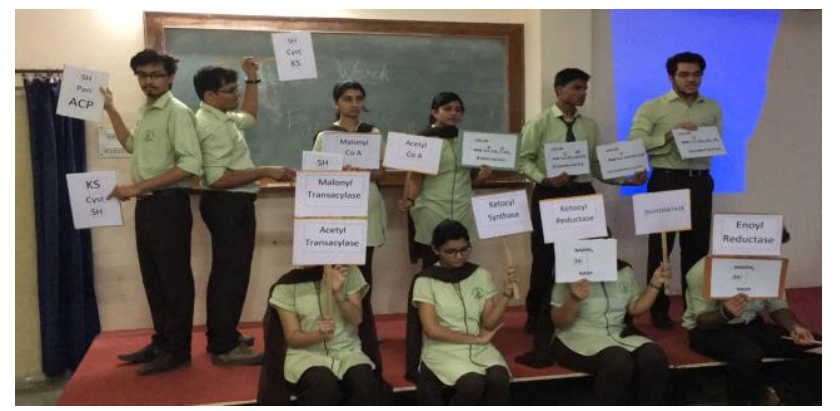

Fig. 3A

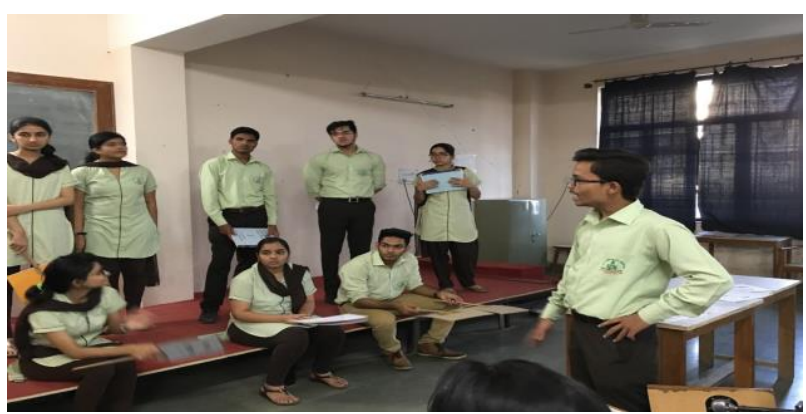

Fig. 3B

Students enacted in front of the class of 140 students and ten teachers attending the session. After the sessions, pre-validated feedback questionnaire was handed over to the all students and teachers. The structured questionnaire was given to the students \& the teachers. A five point Likert scale with a score of $1=$ strongly disagree, $2=$ disagree, $3=$ Neither agree or disagree, $4=$ agree $\& 5=$ strongly agree was used to find out overall perception of the intervention by students \& teachers.

\section{Statistical Analysis}

To study the impact of the intervention feedback questionnaire was administered to the students \& teachers. Likert scale was used to give score from 1to 5 ranging from strongly disagree as one to strongly agree as 5. Final Likert's score was achieved by applying unpaired student's $t$ test.

\section{Results}

Table 1 demonstrates response of students to the questionnaire. Students felt that DE novo synthesis of fatty acid by Fatty acid synthase complex is worthwhile teaching by role play and it helped them to remember all enzymes of FAS-MEC, their working and their action on substrate. They agreed that the concept of loading of enzyme and actions of reduction units are well understood by them. Students strongly agreed that the participation of students in such plays may increase their retention of knowledge with better reproducibility.

As a response to questionnaire in table 2, teachers agreed that topic chosen was worthwhile teaching by Role Play \& it helped students to understand the concept. They strongly appreciated efforts of participating students and felt that they were well prepared for the task and strongly agreed that role play will lead to better retention of knowledge in students. Teachers agreed that role play would helped students in understanding structure \& mechanism FAS complex. Sequence of reactions were well organized and its illustration was clear. They strongly agreed that role play increases teacher student communication.

As response to the questions aimed to find usefulness of role play \& power point presentation we observed following points. Both groups neither agreed or disagreed on the points like teaching with Power point presentation using animation is better than role play but supported that PowerPoint presentation should follow role play. Both group felt that role play is not an outdated method in today's digital era. Teachers disagreed that role play is time consuming while students were neutral. (Fig: 1)

Success of role play lies in that $79 \%$ of students agreed that they would like to participate in such activities further while $90 \%$ of teachers agreed to incorporate role play in their teaching. (Fig. 2)

Table 1: Perception of students for use of role play as a method of teaching

\begin{tabular}{|l|l|c|}
\hline S. No & Question asked to the students & $\begin{array}{c}\text { Student's Likerts } \\
\text { Score Mean } \pm \text { SD }\end{array}$ \\
\hline 1 & Synthesis of fatty acid by Fatty acid synthase complex is worthwhile teaching by Role Play. & $3.94 \pm 0.97$ \\
\hline 2 & Role play helps us to remembers all enzymes of multienzyme complex and their working. & $3.62 \pm 1.12$ \\
\hline 3 & All enzyme and their action on substrate are well understood by role play. & $3.68 \pm 0.96$ \\
\hline 4 & The concept of loading of enzyme and actions of reduction units are well understood. & $3.70 \pm 0.92$ \\
\hline 5 & Teaching by role play is time consuming. & $2.65 \pm 1.15$ \\
\hline 6 & $\begin{array}{l}\text { Participation of students in such plays increases their retention of knowledge with better } \\
\text { reproducibility. }\end{array}$ & $4.27 \pm 0.97$ \\
\hline 7 & Role play is an outdated method of teaching in todays era. & $2.25 \pm 1.04$ \\
\hline
\end{tabular}


Table 2: Perception of teachers towards use of role play as a method of teaching.

\begin{tabular}{|l|l|c|}
\hline S. No & Questions asked to teachers & $\begin{array}{c}\text { Teacher's Likerts } \\
\text { score Mean } \pm \text { SD }\end{array}$ \\
\hline 1 & De-novo synthesis of Fatty acids was worthwhile teaching by Role Play. & $3.7 \pm 1.25$ \\
\hline 2 & Role play helps students to understand concept of this topic. & $3.9 \pm 1.59$ \\
\hline 3 & Role play will lead to better retention of knowledge in students & $4.6 \pm 0.51$ \\
\hline 4 & Participating students were well prepared for the task. & $4.8 \pm 0.42$ \\
\hline 5 & Sequence of reactions were well organized and its illustration was clear. & $4.2 \pm 0.91$ \\
\hline 6 & Teaching by role play is time consuming. & $2.1 \pm 1.37$ \\
\hline 7 & Participation of students in such plays improves teacher student's interaction. & $4.7 \pm 0.48$ \\
\hline 8 & Role play is an outdated method of teaching in today's e era. & $1.7 \pm 0.48$ \\
\hline
\end{tabular}

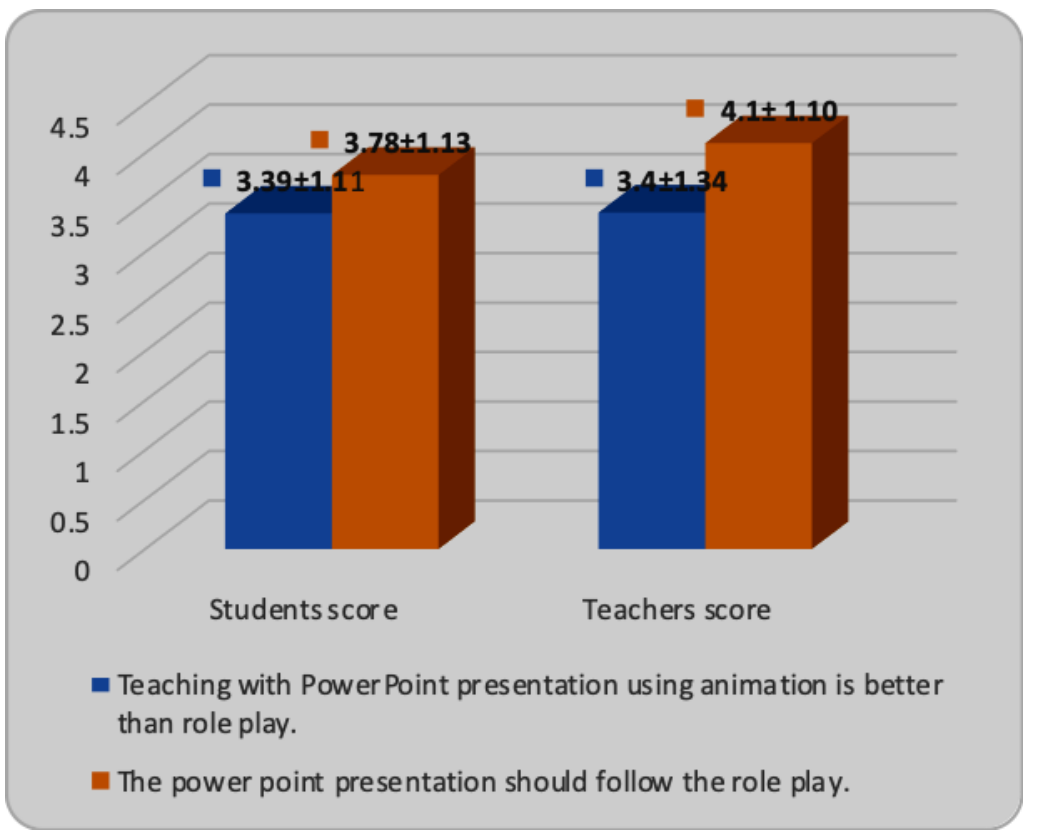

Fig. 1: Students and Teachers view on use of power point presentation with role play.

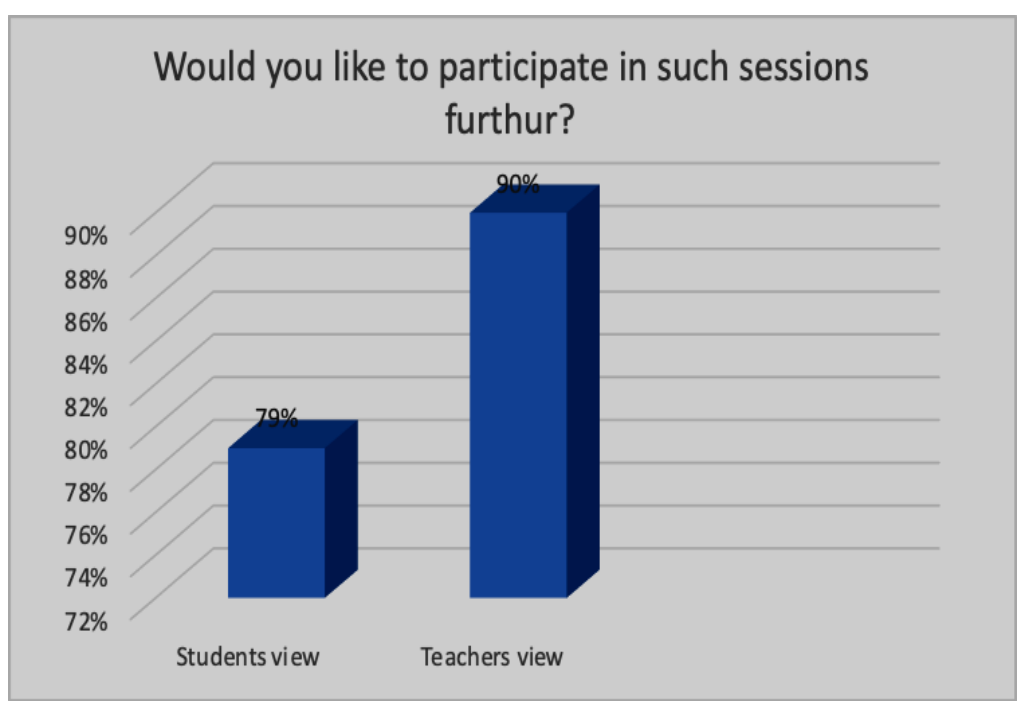

Fig. 2: Willingness of teachers and students to participate in Role play in Future.

\section{Discussion}

Biochemistry deals with various metabolic reactions, their regulations \& clinical applications. To increase clinical competency basic concepts \& metabolic pathways should be understood properly by the students.

Most widely used traditional lectures has strength in organizing and communicating facts and concepts. Being one way process and the absence of using information to 
decide and act on it, e.g. dialog, drawings, reports, prevents the students from using an optimal whole-brain approach. ${ }^{15}$ As per study conducted in the past to find out preference and expectation of teaching learning method in Biochemistry, the most preferred teaching style by the students was interactive followed by formal lectures with the expectation of gradual introduction of the novel approach as the methods of teaching. ${ }^{1}$ Cellular metabolism are the topics that are reported as poorly understood topics by the students and judged to be difficult by many teachers. ${ }^{7}$ To assist students in the learning of Biochemistry, teaching strategy linking macroscopic \& microscopic structures need to be developed. It has been proved that models \& analogies are more effective methods to teach the difficult concept. ${ }^{10}$

Role play is effective method to facilitate learning model that involve cognitive input of students at college and tertiary levels. It provides opportunity to include students different learning style, bringing out their creativity and with the enhancement of conceptual understanding and recall. ${ }^{16}$ Some of the past studies has used role-play to develop students' conceptual understanding in the biological sciences. ${ }^{10-12}$ The present study reinforces the findings of past studies conducted in biochemistry which has implemented role play for difficult topics in Biochemistry. ${ }^{10,11}$ One of them has used different colored pop it beads to simulate enzyme substrate interaction. ${ }^{10}$ Same way interactive role play was used in the form of choreographed dance to increase conceptual understanding in Glycolysis and TCA cycle. ${ }^{11}$ They have reported increase in cognitive understanding of fundamental abstract content which rely on recall of mental image. This has resulted in positive attitude of students towards the topic which seems to be challenging. ${ }^{11}$ In the present study role play, has helped the students to visualize three-dimensional structure of fatty acid synthase complex and their reactions. Hence both the teachers and students agreed that topic chosen for role play was worthwhile for teaching using role play.

Few important guidelines suggested for carrying out role play are in the form of extensive pre-activity planning, activity followed by debriefing. Proper use of props in the form of placards to contextualize the situation, use of proper set up and addition of little humor has made role play effective in the present study. ${ }^{17}$ Same is appreciated by participating Teachers with their positive remarks on conduct of role play. (Table 2)

Simulation-role-play allows students to demonstrate their understanding, explore their views and develop deeper understanding of the phenomena. Moreover, role play acts as an informative tool to aid students understanding and helps them to relate theory to practice. The above-mentioned facts do support participants feelings about retention of knowledge and better reproducibility. This is one of the important feedback which has fulfilled our goal to prepare students to enable students to write the complete metabolic pathway.

Group role play is used to facilitate peer to peer interaction in many students. This indeed, provides opportunities and encourages students to engage in communication with each other ${ }^{5}$. One previous study carried out in Nepal demonstrated positive student feedback for role play which is corresponding to our study. Students reported role plays as an interesting module in improving communication skills. Role plays are not resource intensive and can be considered for use in medical schools in developing nations. ${ }^{18}$ Our teacher's opinion corresponds to the above studies.

In the world of growing digitalization where ample of information is available on the click, teachers must look for new avenues to make subject interesting. For Biochemistry to play a proper role in the curriculum, it needs to be taught through a diversity of modalities that allow its fundamentals to be applied either in learning more complex concepts or in application to clinical problems. Amongst an extensive range of active learning approaches, role-play, can be used by higher education teachers to engage students potentially for enhancing student understanding. ${ }^{19}$ Present study has positive impact on teacher and could motivate them to include role play in their teaching.

Role play is very commonly used in teaching humanities where it was widely regarded as an enjoyable activity which provides a zone of comfort and relaxation. The high enjoyment scores while implementing role play are the documented matter of satisfaction in previous studies. ${ }^{18}$ In addition to that role-play enhances activelistening skills, social problem-solving skills and demonstration of emotional empathy which helps to foster team work even in non-medical fields. ${ }^{20,21}$ Above study further supports enthusiasm in our students to participate in such events as $89 \%$ agreed to participate in such events in future.

Power point is most popular software used in classroom teaching. This topic could have been covered with the Power point presentation with animation. Several studies supported the hypothesis that graphics and animations in power point presentation improve students' recall, recognition \& memory. ${ }^{22,23}$ However, considering neglect of interaction, high speed of presentation reducing participation of students, both groups of our study could not decide which one is better. However, as a reinforcement, participants of our study agreed that power point presentation should follow the role play. ${ }^{24}$ Few past studies also documented that attitudes and learning gains in the role play indicates that it is preferable as a reinforcement technique, although the order does not matter if both lecture and role play are utilized to convey information. ${ }^{25}$ Moreover, Students in larger classes show equivalent learning gains whether they observe or participate in a role play demonstration. ${ }^{25}$ This finding is important as it motivates teachers to use role play as method of teaching in large classes. ${ }^{26}$ Participant of present study demonstrated same impact.

Retrospective data on implementation of active learning methods indicates that though active learning promotes greater student understanding of course material, many barriers still exist that prevent instructors from adopting active learning strategies, including perceptions about 
preparation time, reduced confidence in teaching via a new method, and in-class time investment. ${ }^{26}$ To our great satisfaction our students and teachers did not find role play time consuming.

\section{Conclusion}

Despite growing digitalization constitutional methods of teaching like role play is still appreciated by students and teachers as a useful and effective teaching learning tool. It can be used either independently or in conjunction with other teaching methodology like power point presentation. Role play helps to achieve learning goal by creating mental image of a topic on student's minds. It raises positive inclination of students and teachers by providing healthy communication.

\section{Limitation of Study}

Our study has a limitation that we have designed and developed role play only in one topic with metabolic pathway. We should extend our study by using more role plays in other topics of Biochemistry. More over the same role play can be used as interactive role play on a regular basis.

\section{Source of funding}

None.

\section{Conflict of interest}

None.

\section{References}

1. Dantu Padmasree, Ukey Ujwala U, Kamala Kanta Parhi. Teaching-learning methods in Biochemistry: First MBBS students' preferences and expectations Int J Health Res (In Modern Integrated Medical Sciences) (O), 2015;2(2). ISSN 2394-8612 (P), ISSN 2394-8620

2. Jose Manuel Gonza lez-Sancho, Aurora Sanchez-Pacheco, Marina Lasa, Susana Molina Francisco Vara Luis del Peso. The Use of an Active Learning Approach to Teach Metabolism to Students of Nutrition and Dietetics. Biochem Mol Biol Educ 2013;131-8

3. Hargie O, Dickson D, Boohan M, Hughes K. A survey of communication skills training in UK Schools of Medicine: present practices and prospective proposals. Med Educ 1997;32(1):25-34. doi:10.1046/j.1365-2923.1998.00154. x.

4. Skelton J, Hammond P, Fitzmaurice D, Wiskin C. The acceptability of whole context role-play. Educ Gen Pract. 1997;8(3):206-12.

5. Aubusson P, S Fogwill, R. Barr, L Perkovic. What happens when students do simulation-role-play in science? Res Sci Educ. 1997;27:565-79.

6. Lean J, Moizer J, Towler M, Abbey C. Simulations and games: Use and barriers in higher education. Act Learning Higher Educ 2006;7(3):227-42.

7. Songer C J \& Mintzes J J. Understanding cellular respiration: An analysis of conceptual changes in college Biology. J Res Sci Teaching 1994;31(6):621-37.

8. Sourya Acharya, Samarth Shukla, Neema Acharya, Jayanta Vagha. Role play - an effective tool to teach clinical medicine. Journal of Contemporary Medical Education www.scopemed.org DOI: 10.5455/jcme.20140619111139
9. Kamerade D M. Group role-play as a method of facilitating student to student interaction and making theory relevant. In Practice and Evidence of the Scholarship of Teaching (ECE Conference Special Issue). 2011;6(2): University of Glasgow.

10. Ragsdale F R. \& Predretti K M. Making the rate: Enzyme dynamics using Pop-It Beads. Am Biol Teacher. 2004;66(9),621-6.

11. Ross P M, Tronson D A, \& Ritchie R J. Increasing conceptual understanding of glycolysis \& the Krebs cycle using role-play. Am Biol Teacher 2008;70:163-8.

12. Sturges D, Maurer T W, \& Cole O. Understanding protein synthesis: A role-play approach in large undergraduate human anatomy and physiology classes. Adv Physiol Educ 2009:33(2): 103-10.

13. Robert M, David B, Kathleen B, Peter K, Victor R, Anthony W R. Harper's Illustrated Biochemistry. Twenty Ninth Edition. Mac Graw Hills publications. 216-223.

14. D Vasudevan, S. Shreekumari, K. Vidyanathan. Text books of Biochemistry for Medical students. $8^{\text {th }}$ Edition. Jaypee Publication.2016.198-202

15. Zull, J., The art of changing the brain. Sterling, VA: Stylus Publishing, LLC. 2002.

16. Ross P M, Tronson D A. Towards conceptual understanding: Bringing research finding in to lecture theater in tertiary science teaching. Proceedings of Scholarly Enquiries in to Science Teaching and Learning Symposium, Sydney. Australia. 2004; pp. 52-57.

17. Deepa Rao and Leva Stupans. Exploring the potential of role play in higher education: development of a typology and teacher guidelines. Innovations in Education and Teaching International. 2012;49(4):427-436

18. P Ravi Shankar, Rano M Piryani, Kundan K Singh, Bal Man S Karki. Student feedback about the use of role plays in Sparshanam, a medical humanities module. F1000Research 2012, 1:65 Last updated: 07 AUG 2013 (Nepal)

19. Cherney I D. The effects of active learning on students' memories for course content. Act Learning Higher Educ 2008;9(2):152-71.

20. Beard R L, Salas E, Prince C. Enhancing transfer of training: Using role-play to foster teamwork in the cockpit. Int $J$ Aviation Psychol 1995;5(2):131-43.

21. Van Hasselt V B, Baker M T, Romano S J, Sellers A H, Noesner G W, Smith, S. Development and validation of a roleplay test for assessing crisis (hostage) negotiation skills. Criminal Justice Behav 2005;32:345-61.

22. L J Chan Lin, Attributes of animation for learning scientific knowledge. J Inst Psychol 2000;27:228-38.

23. A Szabo, N Hastings. Using IT in the undergraduate classroom: should we replace the chalkboard with Power Point?" Comput Educ 2000;35:175-87.

24. Ding Xingeng, Liu Jianxiang. Advantages and Disadvantages of PowerPoint in Lectures to Science Students. I.J. Education and Management Engineering 2012, 9, 61-65 Published Online September 2012 in MECS (http://www.mecs-press.net) DOI: 10.5815/ijeme.2012.09.10

25. Samantha L. Elliott. Efficacy of Role Play in Concert with Lecture to Enhance Student Learning of Immunology. $J$ Microbiol Biol Educ, 2010:113-18.

26. Michael J. Faculty perceptions about barriers to active learning. Coll Teaching 2007;55:42-7. 